\title{
Regulation of aldo-keto reductases in human diseases
}

\author{
Wei-Dong Chen and Yanqiao Zhang* \\ Department of Integrative Medical Sciences, Northeast Ohio Medical University, Rootstown, $\mathrm{OH}$, USA
}

\section{Edited by:}

Yi Jin, University of Pennsy/vania, USA

\section{Reviewed by:}

Wen Xie, University of Pittsburgh, USA

Kwang-Huei Lin, Chang-Gung

University, Taiwan

*Correspondence:

Yanqiao Zhang, Department of Integrative Medical Sciences,

Northeast Ohio Medical University,

4209 State Route 44, Rootstown, $\mathrm{OH}$

44272, USA.

e-mail: yzhang@neomed.edu
The aldo-keto reductases (AKRs) are a superfamily of NAD(P)H-linked oxidoreductases, which reduce aldehydes and ketones to their respective primary and secondary alcohols. AKR enzymes are increasingly being recognized to play an important role in the transformation and detoxification of aldehydes and ketones generated during drug detoxification and xenobiotic metabolism. Many transcription factors have been identified to regulate the expression of human AKR genes, which could have profound effects on the metabolism of endogenous mediators and detoxication of chemical carcinogens. This review summarizes the current knowledge on AKR regulation by transcription factors and other mediators in human diseases.

Keywords: aldo-keto reductase, regulation, response element, transcription factor, human disease

\section{INTRODUCTION}

The aldo-keto reductases (AKRs) are a superfamily of $\mathrm{NAD}(\mathrm{P}) \mathrm{H}$ linked oxidoreductases, which primarily catalyze the reduction of aldehydes and ketones to primary and secondary alcohols, respectively (Penning and Drury, 2007). AKRs are generally soluble, cytosolic monomeric $(37 \mathrm{kDa})$ enzymes and are present in both prokaryotes and eukaryotes. These enzymes share a common protein fold, a $(\beta / \alpha) 8$ or a triosephosphate isomerase (TIM)-barrel, and have an active site in the C-terminal face (Jez et al., 1997a,b; Barski et al., 2008). Most AKRs use pyridine nucleotide as cofactors and catalyze simple oxidation-reduction reactions involved in the metabolism of sugar aldehydes, reactive lipid aldehydes, ketoprostaglandins, and ketosteroids.

Aldo-keto reductases consist of 15 families which have more than 100 members (Barski et al., 2008). There are 13 human AKR proteins that fall into 3 families AKR1, AKR6, and AKR7 (Table 1). The detailed information is available at http://www.med.upenn.edu/akr, an AKR superfamily homepage, maintained by Dr. T. Penning at the University of Pennsylvania. The human AKR enzymes include AKR1A1 (aldehyde reductase), AKR1B1 and AKR1B10 (aldose reductases), AKR1C1-C4 (hydroxysteroid dehydrogenases), AKR1D1 (steroid 5 $\beta$-reductase), the AKR6 family (AKR6A3, A5, and $\mathrm{A} 9 ; \mathrm{Kv} \beta$ proteins), and the AKR7 family (AKR7A2 and AKR7A3; aflatoxin aldehyde reductases). These human AKR enzymes can catalyze many metabolic oxidation-reduction reactions of numerous endogenous and exogenous substrates, including glucose, steroids, carcinogens, reactive aldehydes, and a variety of carbonyl-containing drugs. To date, the AKR enzymes have been implicated in a number of human diseases. It is known that AKR1A1, AKR1B10, and AKR1C1-C3 are involved in tobacco-induced carcinogenesis (Hsu et al., 2001; Penning, 2005; Jin and Penning, 2007; Zhang et al., 2008; Liu et al., 2009a). Inhibition of AKR1B1 is able to alleviate diabetic complications. Through mediating oxidative stress-induced inflammatory signals, AKR1B1 plays a role in inflammation-related diseases such as sepsis and colon cancer
(Ramana, 2011). AKR1B1 and AKR1B10 regulate the development and progression of human liver, breast, and lung cancers through detoxifying reactive carbonyls, retinoic acid homeostatic regulation, and lipid metabolism (Liu et al., 2009a; Diez-Dacal et al., 2011). AKR1C1-C3 enzymes are involved in prostate and breast carcinogenesis (Penning and Byrns, 2009). Mutations in AKR1D1 gene in patients lead to neonatal cholestasis, hepatitis, and liver failure (Lemonde et al., 2003; Barski et al., 2008). AKR7A proteins protect liver from acetaminophen-induced hepatotoxicity by enhancing hepatocellular antioxidant defense (Ahmed et al., 2011). Because AKR enzymes are increasingly being recognized to play a role in various diseases, understanding the regulation of human AKR genes may help us develop novel therapeutic approaches. In this review, we summarize the regulation of AKRs by transcription factors, mediators, and pathological conditions.

\section{THE REGULATION OF AKRs}

Many transcription factors have been identified to regulate the expression of human AKR genes, which could have profound effects on the metabolism of endogenous mediators and detoxication of chemical carcinogens. Several classes of transcription enhancer elements have been identified in the upstream promoter region of AKR genes that include nuclear receptor response elements, AP-1 binding sites, the xenobiotic response elements (XRE), osmotic response elements (ORE), estrogen response elements (ERE), and antioxidant response elements (ARE; Ko et al., 1997; Burczynski et al., 1999; Lou et al., 2006; Penning and Drury, 2007).

\section{AKR1A1}

AKR1A1, a ubiquitously expressed enzyme, is a well-known cytosolic, NADPH-dependent and monomeric oxidoreductase. AKR1A1 participates in carbonyl reductions of chemotherapeutic drugs. Protein and mRNA levels of AKR1A1 in irinotecan-resistant LoVo cells are higher than in human colon adenocarcinoma LoVo cells (Peng et al., 2010). Recent studies suggest that overexpression 
Table 1 | Regulation of human aldo-keto reductase.

\begin{tabular}{|c|c|c|c|c|}
\hline Name & Enzyme & Previous symbols & Synonyms & Regulation \\
\hline AKR1A1 & Aldehyde reductase & & ALR, DD3 & hStaf/ZNF143, C/EBP, PPAR $\gamma$, atorvastatin \\
\hline AKR1B1 & Aldose reductase & ALDR1 & $\mathrm{AR}$ & $\begin{array}{l}\text { Thyroid hormone, CREB, NAFT5, Nrf2, } \\
\text { nitric oxide, EGF, TGF } \beta 1 \text {, atorvastatin }\end{array}$ \\
\hline AKR1B10 & Aldose reductase & AKR1B11 & $\begin{array}{l}\text { AKR1B12, ARL-1, HIS, ARL1, } \\
\text { HSI, ALDRLn }\end{array}$ & $\begin{array}{l}\text { Mouse Akr1b7 is regulated by } L X R, P X R \text {, } \\
\text { CAR, FXR }\end{array}$ \\
\hline AKR1C2 & $\begin{array}{l}\text { Dihydrodiol dehydrogenase 2; bile acid } \\
\text { binding protein; 3-alpha hydroxysteroid } \\
\text { dehydrogenase, type III }\end{array}$ & $\mathrm{DDH} 2$ & $\begin{array}{l}\mathrm{DD}, \mathrm{BABP}, \mathrm{DD} 2, \mathrm{HAKRD} \\
\text { MCDR2 }\end{array}$ & $I L-1 \beta$ \\
\hline AKR1C3 & $\begin{array}{l}\text { Aldo-keto reductase family 1, member } \\
\text { C3 (3-alpha hydroxysteroid } \\
\text { dehydrogenase, type II) }\end{array}$ & HSD17B5 & KIAA0119, DDX, HAKRB & IL-6, cadmium, Nrf2 \\
\hline AKR1D1 & Delta 4-3-ketosteroid-5-beta-reductase & SRD5B1 & & Estrogen \\
\hline AKR6A3 & Shaker channel $\beta$-subunit (Kvb1) & & $\begin{array}{l}\text { KCNAB1, KCNA1B, } \\
\text { hKvBeta3, Kvb1.3, hKvb3 }\end{array}$ & Bone morphogenic protein-2 \\
\hline AKR6A5 & Shaker channel $\beta$-subunit (Kvb2) & & $\begin{array}{l}\text { KCNAB2, KCNA2B, } \\
\text { HKvbeta2.1, HKvbeta2.2 }\end{array}$ & \\
\hline AKR6A9 & Shaker channel $\beta$-subunit (Kvb1) & & KCNAB3, KCNA3B & \\
\hline AKR7A2 & Aflatoxin aldehyde reductase & & AFAR & Nrf2, acetaminophen \\
\hline AKR7A3 & Aflatoxin aldehyde reductase & & & Nrf2, acetaminophen \\
\hline
\end{tabular}

References and the regulation of AKRs by pathological conditions can be found in the text.

of AKR1A1 may protect lung epithelial cells against acute toxic effects of polycyclic aromatic hydrocarbon metabolites (Abedin et al., 2012).

Gel-shift assays and chromatin immunoprecipitation assays revealed that $A K R 1 A 1$ is a target gene of transcription factors hStaf/ZNF143 and C/EBP homologous protein (Table 1; Barski et al., 2004; Myslinski et al., 2006). The $\beta$-hydroxy$\beta$-methylglutaryl coenzyme A (HMG-CoA) reductase inhibitor atorvastatin suppresses the expression of AKR1A1 and AKR1B1 in human umbilical vein endothelial cells (HUVEC) but not in human proximal tubular epithelial cells (Ruf et al., 2009). Luciferase reporter assays showed that atorvastatin regulates AKR1A1 promoter activity through an ARE (Ruf et al., 2009). Grip et al. (2002) show that atorvastatin also activates PPAR $\gamma$. The PPAR $\gamma$ binding sites are also found in the AKR1A1 promoter. Thus, atorvastatin may regulate AKR1A1 expression via direct or indirect regulation of AKR1A1 promoter activity.

\section{AKR1B1 AND AKR1B10}

AKR1B1, the most studied AKR family member, is the rate-limiting enzyme of the polyol pathway. AKR1B1 has long been known for its potential role in the development of diabetic complications by driving glucose flux through the polyol pathway (Liu et al., 2009a). Because this enzyme catalyzes the reduction of glucose to a sugar alcohol, many AKR1B1 inhibitors have been developed for the treatment of diabetic complications. Recent reports showed that AKR1B1 is also involved in inflammatory diseases such as atherosclerosis, sepsis, uveitis, and colon carcinogenesis through regulating oxidative stress-induced inflammatory signals (Ramana, 2011; Shoeb et al., 2011). The AKR1B1 and AKR1B10 have $71 \%$ identify in amino acid sequence. These two proteins show overlapped substrate specificity but significantly different tissue expression patterns. AKR1B1 is ubiquitously expressed whereas AKR1B10 is mainly expressed in liver, colon, small intestine, thymus, and adrenal gland. AKR1B10 was identified in 1998. Recent results suggest that AKR1B10 may be a tumor marker of several types of cancers. For example, Wang et al. (2010) reported that smoking can induce up-regulation of AKR1B10 in the airway epithelium, suggesting that increased AKR1B10 expression may be involved in lung carcinogenesis. Increased expression of AKR1B1 and AKR1B10 has been found in human liver, breast, and lung tumors. Thus these two proteins may play a key role in the development and progression of these types of cancers (Liu et al., 2009a; Kropotova et al., 2010).

The AKR1B1 gene is up-regulated in response to thyroid hormone (T3) treatment. Liao et al. (2009) reported that T3bound thyroid hormone receptor (TR) induced AKR1B1 expression through a T3 response element; they also demonstrated that AKR1B1 overexpression in some types of hepatocellular carcinomas (HCCs) was TR-dependent, suggesting that the TR-AKR1B1 
pathway might play a crucial role in the development of HCC. Lefrancois-Martinez et al. (2004) indicated that AKR1B1 expression in human adrenocortical cells may be regulated by the transcription factor cAMP-responsive element-binding protein (CREB). Yang et al. (2006) showed that the expression of AKR1B1 is tightly regulated by the transcription factor nuclear factor of activated T-cells 5 (NFAT5) through binding to OREs in the gene. Recently, the transcription factor nuclear factor-erythroid 2 related factor 2 (Nrf2), a key regulator in the adaptive response to oxidative stress, was shown to regulate the expression of AKR1B1, AKR1B10, and AKR1C1-C3 (Ebert et al., 2011; Nishinaka et al., 2011). Finally, several groups observed that the AKR1B1 expression is upregulated in response to the treatment of nitric oxide (Seo et al., 2000), hydrogen peroxide, methylglyoxal (Yabe-Nishimura et al., 2003), epidermal growth factor, or transforming growth factor- $\beta 1$ (Jiang et al., 2008).

The closest murine ortholog of human AKR1B10 is Akr1b7, which is also expressed in the liver, intestine, and adrenal gland. Murine Akr1b7 shares 89\% amino acid homology with human AKR1B10. There are several nuclear receptor binding sites in the Akrlb7 promoter (Figure 1). Several groups have identified Akrlb7 as a direct target of nuclear receptors, such as liver $\mathrm{X}$ receptor (LXR; Volle et al., 2004), xenobiotic receptors pregnane $\mathrm{X}$ receptor (PXR), constitutive androstane receptor (CAR), and farnesoid X receptor (FXR; Figure 1). The finding that Akrlb7 is highly inducible by PXR and CAR (Liu et al., 2009b), is consistent with the role of Akrlb7 in xenobiotic metabolism and lipid peroxidation. Schmidt et al. (2011) showed that FXR induces Akrlb7 expression in the liver and intestine and that Akr $1 \mathrm{~b} 7$ plays a role in detoxification of specific bile acids. We found that hepatic and intestinal Akrlb7 is highly inducible by FXR and that Akrlb7 has striking effects on lowering blood glucose levels and reducing hepatic lipid accumulation in diabetic mice (Ge et al., 2011). These effects are associated with reduced expression of hepatic gluconeogenic genes and increased very low-density lipoprotein secretion. Our data suggest that AKR1b7 may be a therapeutic target for treatment of diabetes mellitus. It will be intriguing to investigate whether human AKR1B10 also regulates glucose and lipid metabolism.

\section{AKR1C1-C4}

AKR1C1-C4 share over 86\% homology with each other. AKR1C1 is expressed in liver, kidney, and testis. AKR1C2 is mainly expressed in liver, prostate, and mammary gland. AKR1C3 is expressed in liver, brain, kidney, placenta, and testis. AKR1C4 is specifically expressed in liver. These enzymes are involved in the metabolism of steroid hormones (AKR1C1-AKR1C3), prostaglandins (AKR1C3), and bile acids (AKR1C4), and play important roles in the detoxification of drugs and xenobiotics (Ebert et al., 2011). AKR1C1-C3 enzymes may be involved in tobacco-induced prostate and breast carcinogenesis (Penning and Byrns, 2009). Increased expression of AKR1C1 has been detected in human diseases, such as endometriosis (Smuc et al., 2009; Hevir et al., 2011), androgen-independent prostate cancer (Stanbrough et al., 2006), and lung cancer (Hsu et al., 2001). Increased expression of AKR1C3 is found in leukemia (Mahadevan et al., 2006; Birtwistle et al., 2009), prostate cancer (Fung et al., 2006; Stanbrough et al., 2006), and breast cancer (Penning and Byrns, 2009).

AKR1C1 overexpression has been associated with drugresistance in a variety of cancers (Deng et al., 2002, 2004; Chen et al., 2005; Hung et al., 2006). Some anticancer drugs may be metabolized by AKR1C1 due to the high similarity between the chemical structures of these drugs and AKR1C1 substrates (Selga et al., 2008). It has been proposed that increased AKR1C1 activity would detoxify reactive oxygen species induced by drugs such as cisplatin, and could lead to apoptosis-related development of drug-resistance. Selga et al. (2008) suggest that AKR1C1 gene expression is regulated by $\mathrm{Sp} 1$ transcription factor, and suppression of AKR1C1 by RNA interference (RNAi) improves the sensitivity to methotrexate, an antimetabolite drug for the chemotherapy of human malignancies, in methotrexate sensitive HT29 cells. The transcription factor, nuclear factor-Y (NF-Y) has also been reported to directly regulate the basal transcription of AKR1C1 in human ovarian, lung, and liver carcinoma cells (Pallai et al., 2010). Interleukin $1 \beta$ (IL-1 $\beta$ ), a major proinflammatory cytokine, can significantly induce the expression of both AKR1C1 and AKR1C2. Roberson et al. (2011) recently showed that this cytokine can facilitate local progesterone metabolism in a cell type critical for maintaining cervical structure through regulating

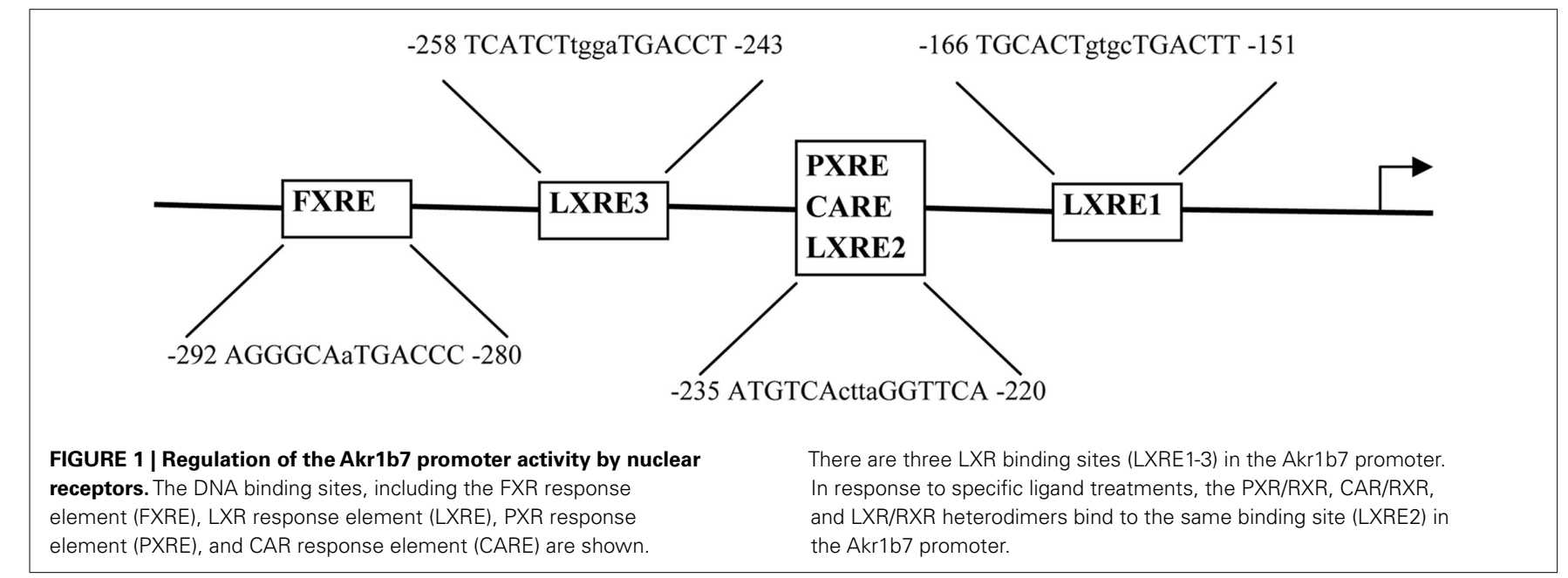


expression of AKR1C1 and AKR1C2. Chun et al. (2009) reported that IL-6 induces the expression of AKR1C3. Cadmium is a toxic metal. Occupational exposure to cadmium is related to the development of lung cancer. Lee et al. (2011) reported that cadmium induces AKR1C3 gene expression through activation of PI3Krelated intracellular signaling pathways and Nrf2 activation. The significance in induction of AKR1C 3 by IL- 6 or cadmium remains to be explored.

It is well documented that liver X receptor (LXR), a nuclear receptor for oxysterols, plays an important role in the regulation of bile acid, lipid, and carbohydrate metabolism and inflammation. AKR1C4 has been demonstrated to be a direct target gene of LXR (Stayrook et al., 2008). Thus, AKR1C4 may play a role in LXR-regulated metabolism or inflammation.

\section{OTHERS}

AKR1D1 catalyzes the 5- $\beta$-reduction of bile acid intermediates and steroid hormones which carry a delta (4)-3-one structure. AKR1D1 is expressed in liver, colon, brain, and testis (Charbonneau and The, 2001; Jin et al., 2011). Deficiency of this enzyme may contribute to hepatic dysfunction (Lemonde et al., 2003; Gonzales et al., 2004; Clayton, 2011). Mutations in human AKR1D1 gene lead to neonatal cholestasis, hepatitis, and liver failure (Barski et al., 2008). In addition, AKR1D1 may play an important role in the degradative metabolism of sex hormones and in regulating multiple hormone-dependent processes. Mode and Rafter (1985) observed different levels of AKR1D1 in the liver of males and females. The ERE was found in the promoter of this gene, suggesting that AKR1D1 may be regulated by estrogen.

AKR6A3, A5, A9 are potassium voltage-gated channel betasubunits, which are expressed in heart and brain. Fantozzi et al. (2006) suggested that bone morphogenetic protein-2 may suppress the expression of AKR6A3. AKR6A3 and AKR6A5 have been associated with epilepsy and impairment of learning and memory (Busolin et al., 2011; Wakasaya et al., 2011). Deletion of AKR6A5 is

\section{REFERENCES}

Abedin, Z., Sen, S., and Field, J. (2012). Aldo-keto reductases protect lung adenocarcinoma cells from the acute toxicity of $\mathrm{B}[\mathrm{a}] \mathrm{P}-$ 7,8-trans-dihydrodiol. Chem. Res. Toxicol. 25, 113-121.

Ahmed, M. M., Wang, T., Luo, Y., Ye, S., Wu, Q., Guo, Z., Roebuck, B. D., Sutter, T. R., and Yang, J. Y. (2011). Aldoketo reductase-7A protects liver cells and tissues from acetaminopheninduced oxidative stress and hepatotoxicity. Hepatology 54, 1322-1332.

Barski, O. A., Papusha, V. Z., Kunkel, G. R., and Gabbay, K. H. (2004). Regulation of aldehyde reductase expression by STAF and CHOP. Genomics 83, 119-129.

Barski, O. A., Tipparaju, S. M., and Bhatnagar, A. (2008). The aldoketo reductase superfamily and its role in drug metabolism and detoxification. Drug Metab. Rev. 40, 553-624.
Birtwistle, J., Hayden, R. E., Khanim, F. L., Green, R. M., Pearce, C., Davies, N. J., Wake, N., Schrewe, H., Ride, J. P., Chipman, J. K., and Bunce, C. M. (2009). The aldo-keto reductase AKR1C3 contributes to 7,12-dimethylbenz(a)anthracene3,4-dihydrodiol mediated oxidative DNA damage in myeloid cells: implications for leukemogenesis. Mutat. Res. 662, 67-74.

Burczynski, M. E., Lin, H. K., and Penning, T. M. (1999). Isoformspecific induction of a human aldoketo reductase by polycyclic aromatic hydrocarbons (PAHs), electrophiles, and oxidative stress: implications for the alternative pathway of $\mathrm{PAH}$ activation catalyzed by human dihydrodiol dehydrogenase. Cancer Res. 59, 607-614.

Busolin, G., Malacrida, S., Bisulli, F., Striano, P., Di Bonaventura, C., Egeo, G., Pasini, E., Cianci, V., Ferlazzo, E., Bianchi, A., Coppola, G., Elia, M.,

often detected in patients who have monosomy 1 p36 deletion syndrome, which is characterized by learning disabilities (Perkowski and Murphy, 2011). By far, little is known about the regulation of AKR6A5 or A9.

AKR7A2 and AKR7A3 are aflatoxin dialdehyde reductases, which share the same chromosomal localization. These enzymes play important roles in bioactivation and biodetoxification (Barski et al., 2008). AKR7A2 is a ubiquitously expressed enzyme, whereas the expression of AKR7A3 is limited to the liver, kidney, colon, pancreas, stomach, endometrium, and adenocarcinoma. Previous studies suggested that AKR7A2 and A3, like other subgroups in the AKR superfamily, are transcriptionally regulated by oxidative stress-responsive transcription factor Nrf2. Ahmed et al. (2011) showed that AKR7A proteins are significantly upregulated in response to acetaminophen exposure and protect liver from acetaminophen-induced hepatotoxicity through enhancing hepatocellular antioxidant defense.

\section{CONCLUSION}

Aldo-keto reductase enzymes play an important role in the transformation and detoxification of aldehydes and ketones. They are involved in bile acid, lipid, carbohydrate, and xenobiotic metabolism, and in inflammation and carcinogenesis. By far, our understanding of the regulation of human AKRs remains limited. Further investigation of the regulation of human AKRs and AKR's functions under normal and pathological conditional will help develop novel therapeutic approaches for treatment of metabolic disorders, inflammation, cancer, and other relevant diseases.

\section{ACKNOWLEDGMENTS}

We apologize to colleagues for not citing their work due to space limitations. This work was supported by grants 1R01HL103227 and 1R15DK088733 from NIH and a Scientist Development Grant $0830255 \mathrm{~N}$ from the American Heart Association (to Yanqiao Zhang).

Mecarelli, O., Gobbi, G., Casellato, S., Marchini, M., Binelli, S., Freri, E., Granata, T., Posar, A., Parmeggiani, A., Vigliano, P., Boniver, C., Aguglia, U., Striano, S., Tinuper, P., Giallonardo, A. T., Michelucci, R., and Nobile, C. (2011). Association of intronic variants of the KCNAB1 gene with lateral temporal epilepsy. Epilepsy Res. 94, 110-116.

Charbonneau, A., and The, V. L. (2001). Genomic organization of a human 5beta-reductase and its pseudogene and substrate selectivity of the expressed enzyme. Biochim. Biophys. Acta 1517, 228-235.

Chen, Y. J., Yuan, C. C., Chow, K. C., Wang, P. H., Lai, C. R., Yen, M. S., and Wang, L. S. (2005). Overexpression of dihydrodiol dehydrogenase is associated with cisplatin-based chemotherapy resistance in ovarian cancer patients. Gynecol. Oncol. 97, 110-117.
Chun, J. Y., Nadiminty, N., Dutt, S., Lou, W., Yang, J. C., Kung, H. J., Evans, C. P., and Gao, A. C. (2009). Interleukin-6 regulates androgen synthesis in prostate cancer cells. Clin. Cancer Res. 15, 4815-4822.

Clayton, P. T. (2011). Disorders of bile acid synthesis. J. Inherit. Metab. Dis. 34, 593-604.

Deng, H. B., Adikari, M., Parekh, H. K., and Simpkins, H. (2004). Ubiquitous induction of resistance to platinum drugs in human ovarian, cervical, germ-cell and lung carcinoma tumor cells overexpressing isoforms 1 and 2 of dihydrodiol dehydrogenase. Cancer Chemother. Pharmacol. 54 301-307.

Deng, H. B., Parekh, H. K., Chow, K. C., and Simpkins, H. (2002). Increased expression of dihydrodiol dehydrogenase induces resistance to cisplatin in human ovarian carcinoma cells. $J$. Biol. Chem. 277, 15035-15043. 
Diez-Dacal, B., Gayarre, J., Gharbi, S., Timms, J. F., Coderch, C., Gago, F., and Perez-Sala, D. (2011). Identification of aldo-keto reductase AKR1B10 as a selective target for modification and inhibition by prostaglandin A(1): implications for antitumoral activity. Cancer Res. 71, 4161-4171.

Ebert, B., Kisiela, M., Wsol, V., and Maser, E. (2011). Proteasome inhibitors MG-132 and bortezomib induce AKR1C1, AKR1C3, AKR1B1, and AKR1B10 in human colon cancer cell lines SW-480 and HT-29. Chem. Biol. Interact. 191, 239-249.

Fantozzi, I., Platoshyn, O., Wong, A. H., Zhang, S., Remillard, C. V., Furtado, M. R., Petrauskene, O. V., and Yuan, J. X. (2006). Bone morphogenetic protein-2 upregulates expression and function of voltagegated $\mathrm{K}+$ channels in human pulmonary artery smooth muscle cells. Am. J. Physiol. Lung Cell Mol. Physiol. 291, L993-L1004.

Fung, K. M., Samara, E. N., Wong, C., Metwalli, A., Krlin, R., Bane, B., Liu, C. Z., Yang, J. T., Pitha, J. V., Culkin, D. J., Kropp, B. P., Penning, T. M., and Lin, H. K. (2006). Increased expression of type 2 3alpha-hydroxysteroid dehydrogenase/type 5 17beta-hydroxysteroid dehydrogenase (AKR1C3) and its relationship with androgen receptor in prostate carcinoma. Endocr. Relat. Cancer 13, 169-180.

Ge, X., Yin, L., Ma, H., Li, T., Chiang, J. Y., and Zhang, Y. (2011). Aldoketo reductase $1 \mathrm{~B} 7$ is a target gene of FXR and regulates lipid and glucose homeostasis. J. Lipid Res. 52, 1561-1568.

Gonzales, E., Cresteil, D., Baussan, C., Dabadie, A., Gerhardt, M. F., and Jacquemin, E. (2004). SRD5B1 (AKR1D1) gene analysis in delta(4)3-oxosteroid 5beta-reductase deficiency: evidence for primary genetic defect. J. Hepatol. 40, 716-718.

Grip, O., Janciauskiene, S., and Lindgren, S. (2002). Atorvastatin activates PPAR-gamma and attenuates the inflammatory response in human monocytes. Inflamm. Res. 51, 58-62.

Hevir, N., Vouk, K., Sinkovec, J., Ribic-Pucelj, M., and Rizner, T. L. (2011). Aldo-keto reductases AKR1C1, AKR1C2 and AKR1C3 may enhance progesterone metabolism in ovarian endometriosis. Chem. Biol. Interact. 191, 217-226.

Hsu, N. Y., Ho, H. C., Chow, K. C., Lin, T. Y., Shih, C. S., Wang, L. S., and Tsai, C. M. (2001). Overexpression of dihydrodiol dehydrogenase as a prognostic marker of non-small cell lung cancer. Cancer Res. 61, 2727-2731.

Hung, J. J., Chow, K. C., Wang, H. W., and Wang, L. S. (2006). Expression of dihydrodiol dehydrogenase and resistance to chemotherapy and radiotherapy in adenocarcinoma cells of lung. Anticancer Res. 26, 2949-2955.

Jez, J. M., Bennett, M. J., Schlegel, B. P., Lewis, M., and Penning, T. M. (1997a). Comparative anatomy of the aldo-keto reductase superfamily. Biochem. J. 326(Pt 3), 625-636.

Jez, J. M., Flynn, T. G., and Penning, T. M. (1997b). A new nomenclature for the aldo-keto reductase superfamily. Biochem. Pharmacol. 54, 639-647.

Jiang, T., Qu, J. J., Nishinaka, T., and Zhang, N. (2008). Transcription factor AP-1 regulates TGF-beta(1)induced expression of aldose reductase in cultured human mesangial cells. Nephrology (Carlton) 13, 212-217.

Jin, Y., Mesaros, A. C., Blair, I. A., and Penning, T. M. (2011). Stereospecific reduction of 5betareduced steroids by human ketosteroid reductases of the AKR (aldoketo reductase) superfamily: role of AKR1C1-AKR1C4 in the metabolism of testosterone and progesterone via the 5beta-reductase pathway. Biochem. J. 437, 53-61.

Jin, Y., and Penning, T. M. (2007). Aldo-keto reductases and bioactivation/detoxification. Annu. Rev. Pharmacol. Toxicol. 47, 263-292.

Ko, B. C., Ruepp, B., Bohren, K. M., Gabbay, K. H., and Chung, S. S. (1997). Identification and characterization of multiple osmotic response sequences in the human aldose reductase gene. J. Biol. Chem. 272, 16431-16437.

Kropotova, E. S., Tychko, R. A., Zinov'Eva, O. L., Zyrianova, A. F., Khankin, S. L., Cherkes, V. L., Aliev, V. A., Beresten, S. F., Oparina, N., and Mashkova, T. D. (2010). Downregulation of AKR1B10 gene expression in colorectal cancer. Mol. Biol. (Mosk.) 44, 243-250.

Lee, Y. J., Lee, G. J., Baek, B. J., Heo, S. H., Won, S. Y., Im, J. H., Cho, M. K., Nam, H. S., and Lee, S. H. (2011). Cadmium-induced up-regulation of aldo-keto reductase 1C3 expression in human nasal septum carcinoma RPMI-2650 cells: involvement of reactive oxygen species and phosphatidylinositol 3-kinase/Akt. Environ. Toxicol. Pharmacol. 31, 469-478.
Lefrancois-Martinez, A. M., Bertherat, J., Val, P., Tournaire, C., GalloPayet, N., Hyndman, D., Veyssiere, G., Bertagna, X., Jean, C., and Martinez, A. (2004). Decreased expression of cyclic adenosine monophosphate-regulated aldose reductase (AKR1B1) is associated with malignancy in human sporadic adrenocortical tumors. J. Clin. Endocrinol. Metab. 89, 3010-3019.

Lemonde, H. A., Custard, E. J., Bouquet, J., Duran, M., Overmars, H., Scambler, P. J., and Clayton, P. T. (2003). Mutations in SRD5B1 (AKR1D1), the gene encoding delta(4)-3oxosteroid 5beta-reductase, in hepatitis and liver failure in infancy. Gut 52, 1494-1499.

Liao, C. S., Tai, P. J., Huang, Y. H., Chen, R. N., Wu, S. M., Kuo, L. W., Yeh, C. T., Tsai, M. M., Chen, W. J., and Lin, K. H. (2009). Regulation of AKR1B1 by thyroid hormone and its receptors. Mol. Cell. Endocrinol.307, 109-117.

Liu, J., Wen, G., and Cao, D. (2009a). Aldo-keto reductase family 1 member B1 inhibitors: old drugs with new perspectives. Recent Pat. Anticancer Drug. Discov. 4, 246-253.

Liu, M. J., Takahashi, Y., Wada, T., He, J., Gao, J., Tian, Y., Li, S., and Xie, W. (2009b). The aldo-keto reductase Akrlb7 gene is a common transcriptional target of xenobiotic receptors pregnane $\mathrm{X}$ receptor and constitutive and rostane receptor. Mol. Pharmacol. 76, 604-611.

Lou, H., Du, S., Ji, Q., and Stolz, A. (2006). Induction of AKR1C2 by phase II inducers: identification of a distal consensus antioxidant response element regulated by NRF2. Mol. Pharmacol. 69 , 1662-1672.

Mahadevan, D., DiMento, J., Croce, K. D., Riley, C., George, B., Fuchs, D., Mathews, T., Wilson, C., and Lobell, M. (2006). Transcriptosome and serum cytokine profiling of an atypical case of myelodysplastic syndrome with progression to acute myelogenous leukemia. Am. J. Hematol. 81, 779-786.

Mode, A., and Rafter, I. (1985). The sexually differentiated delta 4-3ketosteroid 5 beta-reductase of rat liver. Purification, characterization, and quantitation. J. Biol. Chem. 260, 7137-7141.

Myslinski, E., Gerard, M. A., Krol, A., and Carbon, P. (2006). A genome scale location analysis of human Staf/ZNF143-binding sites suggests a widespread role for human Staf/ZNF143 in mammalian promoters. J. Biol. Chem. 281, 39953-39962.

Nishinaka, T., Miura, T., Okumura, M., Nakao, F., Nakamura, H., and Terada, T. (2011). Regulation of aldo-keto reductase AKR1B10 gene expression: involvement of transcription factor Nrf2. Chem. Biol. Interact. 191, 185-191.

Pallai, R., Simpkins, H., Chen, J., and Parekh, H. K. (2010). The CCAAT box binding transcription factor, nuclear factor-Y (NF-Y) regulates transcription of human aldo-keto reductase $1 \mathrm{Cl}$ (AKR1C1) gene. Gene 459, 11-23.

Peng, X. C., Gong, F. M., Wei, M., Chen, X., Chen, Y., Cheng, K., Gao, F., Xu, F., Bi, F., and Liu, J. Y. (2010). Proteomic analysis of cell lines to identify the irinotecan resistance proteins. J. Biosci. 35, 557-564.

Penning, T. M. (2005). AKR1B10: a new diagnostic marker of non-small cell lung carcinoma in smokers. Clin. Cancer Res. 11, 1687-1690.

Penning, T. M., and Byrns, M. C. (2009). Steroid hormone transforming aldoketo reductases and cancer. Ann. N. Y. Acad. Sci. 1155, 33-42.

Penning, T. M., and Drury, J. E. (2007). Human aldo-keto reductases: function, gene regulation, and single nucleotide polymorphisms. Arch. Biochem. Biophys. 464, 241-250.

Perkowski, J. J., and Murphy, G. G. (2011). Deletion of the mouse homolog of KCNAB2, a gene linked to monosomy $1 \mathrm{p} 36$, results in associative memory impairments and amygdala hyperexcitability. J. Neurosci. 31, 46-54.

Ramana, K. V. (2011). Aldose reductase: new insights for an old enzyme. Biomol. Concepts 2, 103-114.

Roberson, A. E., Hyatt, K., Kenkel, C., Hanson, K., and Myers, D. A. (2011). Interleukin lbeta regulates progesterone metabolism in human cervical fibroblasts. Reprod. Sci. doi: 10.1177/1933719111419246

Ruf, T. F., Quintes, S., Sternik, P., and Gottmann, U. (2009). Atorvastatin reduces the expression of aldo-keto reductases in HUVEC and PTEC. A new approach to influence the polyol pathway. Clin. Invest. Med.32, E219-E228.

Schmidt, D. R., Schmidt, S., Holmstrom, S. R., Makishima, M., Yu, R. T., Cummins, C. L., Mangelsdorf, D. J., and Kliewer, S. A. (2011). AKR1B7 is induced by the farnesoid $\mathrm{X}$ receptor and metabolizes bile acids. J. Biol. Chem. 286, 2425-2432.

Selga, E., Noe, V., and Ciudad, C. J. (2008). Transcriptional regulation of aldo-keto reductase $1 \mathrm{C} 1$ in HT29 
human colon cancer cells resistant to methotrexate: role in the cell cycle and apoptosis. Biochem. Pharmacol. 75, 414-426.

Seo, H. G., Nishinaka, T., and YabeNishimura, C. (2000). Nitric oxide up-regulates aldose reductase expression in rat vascular smooth muscle cells: a potential role for aldose reductase in vascular remodeling. Mol. Pharmacol. 57, 709-717.

Shoeb, M., Yadav, U. C., Srivastava, S. K., and Ramana, K. V. (2011). Inhibition of aldose reductase prevents endotoxin-induced inflammation by regulating the arachidonic acid pathway in murine macrophages. Free Radic. Biol. Med. 51, 1686-1696.

Smuc, T., Hevir, N., Ribic-Pucelj, M., Husen, B., Thole, H., and Rizner, T. L. (2009). Disturbed estrogen and progesterone action in ovarian endometriosis. Mol. Cell. Endocrinol. 301, 59-64.

Stanbrough, M., Bubley, G. J., Ross, K., Golub, T. R., Rubin, M. A., Penning, T. M., Febbo, P. G., and Balk, S. P. (2006). Increased expression of genes converting adrenal androgens to testosterone in androgen-independent prostate cancer. Cancer Res. 66, 2815-2825.

Stayrook, K. R., Rogers, P. M., Savkur, R. S., Wang, Y., Su, C., Varga, G., Bu, X., Wei, T., Nagpal, S., Liu, X. S., and Burris, T. P. (2008). Regulation of human 3 alpha-hydroxysteroid dehydrogenase (AKR1C4) expression by the liver $\mathrm{X}$ receptor alpha. Mol. Pharmacol. 73, 607-612.

Volle, D. H., Repa, J. J., Mazur, A., Cummins, C. L., Val, P., HenryBerger, J., Caira, F., Veyssiere, G., Mangelsdorf, D. J., and Lobaccaro, J. M. (2004). Regulation of the aldo-keto reductase gene akrlb7 by the nuclear oxysterol receptor LXRalpha (liver X receptor-alpha) in the mouse intestine: putative role of LXRs in lipid detoxification processes. Mol. Endocrinol. 18, 888-898.

Wakasaya, Y., Kawarabayashi, T., Watanabe, M., Yamamoto-Watanabe, Y., Takamura, A., Kurata, T., Murakami, T., Abe, K., Yamada, K., Wakabayashi, K., Sasaki, A., Westaway, D., Hyslop, P. S., Matsubara, E., and Shoji, M.
(2011). Factors responsible for neurofibrillary tangles and neuronal cell losses in tauopathy. J. Neurosci. Res. 89, 576-584.

Wang, R., Wang, G., Ricard, M. J., Ferris, B., Strulovici-Barel, Y., Salit, J., Hackett, N. R., Gudas, L. J., and Crystal, R. G. (2010). Smokinginduced upregulation of AKR1B10 expression in the airway epithelium of healthy individuals. Chest 138 1402-1410.

Yabe-Nishimura, C., Nishinaka, T. Iwata, K., and Seo, H. G. (2003). Upregulation of aldose reductase by the substrate, methylglyoxal. Chem. Biol. Interact. 143-144, 317-323.

Yang, B., Hodgkinson, A. D., Oates, P. J., Kwon, H. M., Millward, B. A., and Demaine, A. G. (2006). Elevated activity of transcription factor nuclear factor of activated T-cells 5 (NFAT5) and diabetic nephropathy. Diabetes 55, 1450-1455.

Zhang, L., Lee, J. J., Tang, H., Fan, Y. H., Xiao, L., Ren, H., Kurie, J., Morice, R. C., Hong, W. K., and Mao, L. (2008). Impact of smoking cessation on global gene expression in the bronchial epithelium of chronic smokers. Cancer Prev. Res. (Phila.) 1, 112-118.

Conflict of Interest Statement: The authors declare that the research was conducted in the absence of any commercial or financial relationships that could be construed as a potential conflict of interest.

Received: 30 November 2011; paper pending published: 05 January 2012; accepted: 20 February 2012; published online: 09 March 2012.

Citation: Chen W-D and Zhang Y (2012) Regulation of aldo-keto reductases in human diseases. Front. Pharmacol. 3:35. doi: 10.3389/fphar.2012.00035

This article was submitted to Frontiers in Experimental Pharmacology and Drug Discovery, a specialty of Frontiers in Pharmacology.

Copyright $\odot 2012$ Chen and Zhang. This is an open-access article distributed under the terms of the Creative Commons Attribution Non Commercial License, which permits non-commercial use, distribution, and reproduction in other forums, provided the original authors and source are credited. 